\title{
USO DO REGULADOR DE CRESCIMENTO ETIL-TRINEXAPAC EM ARROZ DE TERRAS ALTAS ( $\left.{ }^{1}\right)$
}

\author{
VAGNER DO NASCIMENTO $\left({ }^{2}\right)$; ORIVALDO ARF $\left({ }^{2 *}\right)$; MATHEUS GUSTAVO DA SILVA $\left({ }^{2}\right)$; \\ FLÁVIO FERREIRA DA SILVA BINOTTI $\left({ }^{2}\right)$; RICARDO ANTÔNIO FERREIRA RODRIGUES $\left({ }^{2}\right)$; \\ RITA DE CÁSSIA FELIX ALVAREZ $\left({ }^{3}\right)$
}

\begin{abstract}
RESUMO
O trabalho foi desenvolvido com o objetivo de avaliar o uso de doses de etil-trinexapac (0; 75; $150 ; 225$ e $300 \mathrm{~g} \mathrm{ha}^{-1}$ de i.a.) e épocas de aplicação (perfilhamento ativo, entre o perfilhamento ativo e a diferenciação floral e na diferenciação floral) no desenvolvimento e na produtividade da cultura do arroz de terras altas. O experimento foi desenvolvido no município de Selvíria (MS), durante o ano agrícola de 2006/2007. Concluiu-se que a aplicação de $150 \mathrm{~g} \mathrm{ha}^{-1}$ de etil-trinexapac na fase da diferenciação floral do arroz cultivar Primavera reduz a altura de plantas, em média 0,40 m, em relação à aplicação nas fases do perfilhamento ativo e, entre o perfilhamento ativo e a diferenciação floral, com ausência de acamamento; o etil-trinexapac, em doses acima $150 \mathrm{~g} \mathrm{ha}^{-1}$, promove maior número de grãos chochos, reduzindo a produtividade de grãos, quando aplicado na fase da diferenciação floral e, a dose de $150 \mathrm{~g}^{\text {ha }}{ }^{-1}$ de etiltrinexapac em qualquer época de aplicação não interfere na produtividade da cultura.
\end{abstract}

Palavras-chave: Oryza sativa L., reguladores vegetais, irrigação por aspersão, giberelina.

\section{ABSTRACT \\ USE OF TRINEXAPAC-ETHYL GROWTH REGULATOR IN UPLAND RICE}

This work was developed with the objective of evaluating the use of trinexapac-ethyl doses $(0,75$, 150,225 and $300 \mathrm{~g}$ of the a.i. $\mathrm{ha}^{-1}$ ) and application times (active tillering, between active tillering and floral differentiation and at floral differentiation) in upland rice crop development and yield. The experiment was carried out in Selvíria-MS, during the agricultural year of 2006/07. Application of $150 \mathrm{~g}$ $\mathrm{ha}^{-1}$ of trinexapac-ethyl in Primavera rice cultivar at panicle initiation differentiation reduces plants height, $0.40 \mathrm{~m}$ on average comparing to other times, with lodging absence. Trinexapac-ethyl promotes lange number of abnormal grains, reduction of grain yields in doses above $150 \mathrm{~g} \mathrm{ha}^{-1}$, when applied in panicle initiation differentiation stadium. Application of $150 \mathrm{~g} \mathrm{ha}^{-1}$ of trinexapac-ethyl at any time does not interfere in crop yield.

Key words: Oryza sativa L., plant growth regulators, sprinkler irrigation, gibberellin.

${ }^{1}$ ) Recebido para publicação em 5 de novembro de 2007 e aceito em 28 de maio de 2009.

( $\left.{ }^{2}\right)$ FEIS/UNESP, Curso de Agronomia, Caixa Postal 31, 15385-000 Ilha Solteira (SP).E-mail: vagner@gmail.com; arf@agr.feis.unesp.br $\left(^{*}\right)$ Autor correspondente; matheus@agr.feis.unesp.br; ricardo@agr.feis.unesp.br

$\left({ }^{3}\right)$ Universidade Federal do Mato Grosso do Sul, UFMS, Curso de Agronomia, Caixa Postal 112, 79560-000 Chapadão do Sul (MS). E-mail: rcalvarez@pop.com.br 


\section{INTRODUÇÃO}

A produção do arroz de terras altas, irrigado por aspersão, tem estimulado o uso de fertilizantes nitrogenados, que associado ao adequado suprimento de água pode resultar em maior altura das plantas e índices de até $100 \%$ de acamamento. Dentre as formas para solucionar o problema de acamamento estão o uso de cultivares resistentes, o manejo adequado da água e do nitrogênio. É importante ressaltar que os agricultores dão preferência a algumas cultivares pelos grãos do tipo agulhinha, os quais têm propensão ao acamamento.

Outra possibilidade para reduzir a altura de plantas de arroz de terras altas, e consequentemente o acamamento, seria a aplicação de reguladores vegetais. Na literatura tem se verificado a viabilidade do uso de reguladores vegetais em culturas anuais, como o trigo; algodão e cana-de-açúcar. Entretanto, essas informações são escassas para a cultura do arroz. Os reguladores vegetais são compostos sintéticos aplicados sobre as plantas, para obtenção de diversos efeitos, tais como o de promover, retardar ou inibir o crescimento vegetativo, sem diminuição na produtividade (RADEMACHER, 2000; BIASI, 2002). A maioria dos reguladores que atuam como retardantes vegetais age por inibição da biossíntese de giberelinas e outros hormônios que entre várias ações promovem o alongamento celular (DAvies, 1995). O etil-trinexapac é um regulador com forte ação na inibição da alongação dos entrenós, o que reduz a estatura da planta e evita, dessa forma, o acamamento e perdas na produtividade associadas a esse fenômeno (NAQVI, 1994; TAIZ e ZEIGER, 1998).

Resultados recentes de resistência ao acamamento, relativos à avaliação do efeito do etiltrinexapac em várias doses de aplicação, foram obtidos com a cultura do trigo. Neste estudo, chuvas e ventos fortes durante o ciclo da cultura foram responsáveis pelo acamamento, principalmente nos tratamentos que não receberam o redutor de crescimento (EMBRAPA, 2003). Os efeitos do regulador de crescimento sobre o algodoeiro dependem de vários fatores, podendo-se destacar: temperatura; população de plantas; época de semeadura; cultivar; época de aplicação e doses utilizadas (YORK, 1983; REDDY et al., 1990; Reddy et al.,1992; Wallace, 1993; Carvalho et al., 1994). O etil-trinexapac também é utilizado como maturador de cana-de-açúcar e promove aumento de rendimento de açúcar sem impacto negativo na qualidade do caldo, no conteúdo de fibras ou na massa da cana. Em adição a estes benefícios, a aplicação de etil-trinexapac não afeta a produção de perfilhos, altura da planta ou o diâmetro dos colmos, na safra seguinte (RESENDE et al., 2001).
$\mathrm{Na}$ busca de resultados que evidenciem sua utilização adequada, objetivou-se avaliar o efeito de doses e as épocas de aplicação de etil-trinexapac no desenvolvimento e na produtividade da cultura do arroz de terras altas em preparo convencional do solo, visando reduzir a altura e evitar possível acamamento das plantas de arroz ao longo do ciclo.

\section{MATERIAL E MÉTODOS}

O trabalho foi realizado no município de Selvíria, MS $\left(20^{\circ} 22^{\prime} \mathrm{S} ; 5^{\circ} 22^{\prime} \mathrm{O}\right.$ e altitude de $\left.335 \mathrm{~m}\right)$, no ano agrícola 2006/2007. O solo do local é do tipo Latossolo Vermelho Distrófico, textura argilosa (EMBRAPA, 1999). A precipitação pluvial média anual é de $1370 \mathrm{~mm}$, a temperatura média anual, de 23,5 ${ }^{\circ} \mathrm{C}$ e a umidade relativa do ar média anual oscila entre 70 e $80 \%$. Os valores diários da precipitação pluvial e temperatura do ar, máxima e mínima, foram registrados durante o período de manejo do experimento de arroz de terras, no ano agrícola de 2006/2007 (Figura 1).

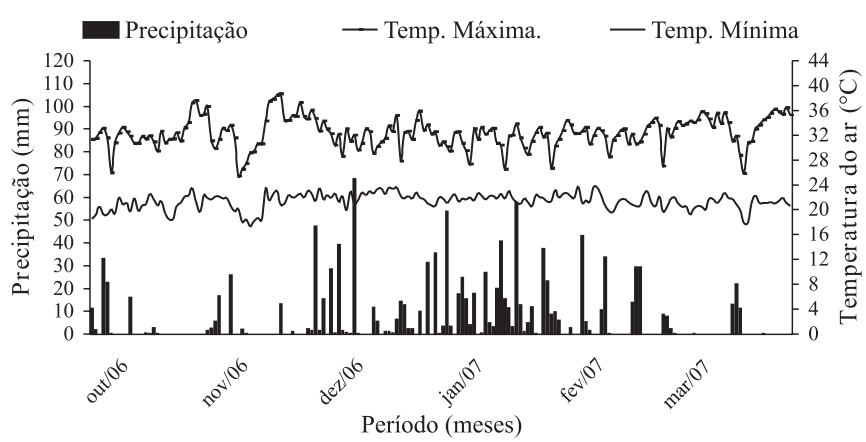

Figura 1. Variação diária da precipitação pluvial e da temperatura máxima e mínima do ar, durante o período de outubro de 2006 a março de 2007.

Antes da instalação do experimento foi coletada amostra composta, originada de 20 amostras simples, do solo da área experimental, na camada de 0 a $0,20 \mathrm{~m}$. A análise da fertilidade do solo, segundo método descrito em Raij e QuAGgio (1983), revelou os seguintes valores: $\mathrm{MO}=13 \mathrm{~g} \mathrm{dm}^{-3} ; \mathrm{P}_{\text {resina }}=28 \mathrm{mg}$ $\mathrm{dm}^{-3} ; \mathrm{pH}\left(\mathrm{CaCl}_{2}\right)=4,9 ; \mathrm{K}^{+}=3,1 \mathrm{mmol}_{\mathrm{c}} \mathrm{dm}^{-3} ; \mathrm{Ca}^{+2}=$ $16 \mathrm{mmol}_{\mathrm{c}} \mathrm{dm}^{-3} ; \mathrm{Mg}^{+2}=4 \mathrm{mmol}_{\mathrm{c}} \mathrm{dm}^{-3} ; \mathrm{H}+\mathrm{Al}=20$ $\mathrm{mmol}_{\mathrm{c}} \mathrm{dm}^{-3} \mathrm{e} \mathrm{V}=54 \%$.

O delineamento experimental foi em blocos casualizados disposto em esquema fatorial $5 \times 3$. Os tratamentos foram constituídos pela combinação de cinco doses de etil-trinexapac $(0,75,150,225$ e $300 \mathrm{~g}$ ha $^{-1}$ de i.a.), aplicado em três fases de desenvolvimento das plantas (perfilhamento ativo; entre o perfilhamento ativo e a diferenciação floral e na diferenciação floral), com quatro repetições. 
O experimento foi instalado em área previamente cultivada com milho (outubro a março, do ano anterior) e após o pousio no período do inverno. O preparo do solo da área foi o convencional, com escarificação e gradagem niveladora. As parcelas foram constituídas por 6 linhas de $6,0 \mathrm{~m}$ de comprimento, espaçadas de 0,35 m. A área útil foi constituída por quatro linhas centrais, desprezando $0,50 \mathrm{~m}$ em ambas as extremidades de cada linha. A adubação básica nos sulcos de semeadura foi calculada de acordo com as características químicas do solo e levando-se em consideração as recomendações de CANTARELla e FURLANI (1996), sendo constituída de $150 \mathrm{~kg} \mathrm{ha}^{-1}$ da formulação 08-28-16. A semeadura foi realizada mecanicamente em 06 de novembro de 2006, considerando um estande final de 180 plantas por metro quadrado. O tratamento de sementes foi realizado com thiodicarb + óxido de zinco $(450+375 \mathrm{~g} 100 \mathrm{~kg}$ de sementes de i.a.).

$\mathrm{O}$ adubo nitrogenado, utilizando como fonte a uréia, na dose de $50 \mathrm{~kg} \mathrm{ha}^{-1}$ de $\mathrm{N}$, foi aplicado 29 dias após a emergência (DAE) das plântulas. Utilizouse a cultivar Primavera, plantas do tipo intermediário, cujas características são: porte médio (1,0 a 1,2 m); ciclo curto (112 dias); 80 dias da emergência ao florescimento e moderadamente suscetível ao acamamento (BRESEGHELLO et al., 1998).

A área foi irrigada com sistema fixo de irrigação convencional por aspersão com vazão de $3,3 \mathrm{~mm} \mathrm{~h}^{-1}$ nos aspersores. No manejo de água foram utilizados três coeficientes de cultura $(\mathrm{Kc})$, distribuídos em quatro períodos compreendidos entre a emergência e a colheita. Para a fase vegetativa foi utilizado o valor de 0,4; para a fase reprodutiva foram dois valores de Kc, o inicial de 0,7 e o final de 1,0 e para a fase de maturação estes valores foram invertidos, ou seja, o inicial de 1,0 e o final de 0,7 (Rodrigues et al., 2004).

O regulador vegetal foi aplicado na forma de jato dirigido, com pulverizador manual tipo costal com volume de calda aproximado de $200 \mathrm{~L} \mathrm{ha}^{-1}$, utilizando-se bico hidráulico, tipo jato cônico vazio. As aplicações foram realizadas no período da manhã, das 8 às $9 \mathrm{~h}$, com ausência ou pouca incidência de vento, usando um anteparo para evitar deriva para outras parcelas.

O controle de plantas daninhas foi realizado com a utilização de herbicidas aplicados com pulverizador costal. Logo após a semeadura, aplicouse o herbicida pendimethalin (1400 $\mathrm{g} \mathrm{ha}^{-1}$ de i.a.) em pré-emergência. Já em pós-emergência, o controle químico foi realizado utilizando o herbicida metsulfuron methyl $\left(2,0 \mathrm{~g} \mathrm{ha}^{-1}\right.$ do i.a. $)$. As demais plantas daninhas não controladas pelos herbicidas foram eliminadas com auxílio de enxada.
As avaliações realizadas, por parcela, foram: florescimento - dias transcorridos entre a emergência e a floração de $50 \%$ das plantas; ciclo - dias transcorridos entre a emergência e a maturação de 90\% das panículas; altura de plantas - média das distâncias da superfície do solo até a extremidade superior da panícula mais alta, determinada em 10 plantas ao acaso; acamamento de plantas - obtido por observações visuais na fase de maturação, utilizandose a seguinte escala de notas: $0=$ sem acamamento; 1 $=$ até $5 \%$ de plantas acamadas; $2=5 \%$ a $25 \%, 3=25 \%$ a $50 \% ; 4=50 \%$ a $75 \%$ e $5=75 \%$ a $100 \%$; nitrogênio nas folhas - coletados 30 limbos foliares (folha bandeira), no início do florescimento, que após secagem em estufa, foram moídos e submetidos à digestão sulfúrica (Malavolta et al., 1997); número de colmos e de panículas por metro quadrado contagem de colmos ou panículas em 1,0 $\mathrm{m}$ de fileira de plantas e posteriormente convertido em colmos ou panículas por metro quadrado; perfilhamento útil relação entre número de panículas e colmos por metro quadrado; número total de grãos por panícula contagem dos grãos de 20 panículas coletadas no momento da colheita; número de grãos cheios e chochos por panícula - contagem de grãos cheios e chochos após separação dos mesmos por fluxo de ar, obtidos com as amostras utilizadas para a determinação do número total de grãos ; massa de cem grãos - massa de duas amostras de cem grãos; massa hectolítrica - determinada em balança especial para massa hectolítrica, utilizando-se duas amostras e, produtividade de grãos - massa dos grãos provenientes da área útil, convertida em $\mathrm{kg} \mathrm{ha}^{-1}$. Os valores das massas foram corrigidos para umidade de $13 \%$ (base úmida).

Os dados foram submetidos à análise de variância e, posteriormente, à análise de regressão polinomial para o fator quantitativo (doses do regulador crescimento) e teste de Tukey para o fator qualitativo (épocas de aplicação do regulador vegetal).

\section{RESULTADOS E DISCUSSÃO}

A emergência das plântulas ocorreu em 12 de novembro de 2006 aos seis dias após a semeadura e de maneira uniforme em todas as parcelas.

Pelos resultados de floração e colheita expressos em dias após a emergência das plântulas, verificou-se interação significativa entre época de aplicação e doses do regulador (Tabela 1). Observando épocas dentro de doses, verificou-se que em doses superiores a $75 \mathrm{~g} \mathrm{ha}^{-1}$ houve diferença para as épocas de aplicação, sendo constatado maior número de dias para ocorrer a floração para a aplicação na fase da diferenciação floral e menor na fase do perfilhamento ativo. 
Tabela 1. Interação entre doses do regulador de crescimento e épocas de aplicação em relação ao número de dias da emergência à floração e da emergência a colheita

\begin{tabular}{|c|c|c|c|c|c|c|}
\hline \multirow{2}{*}{ Épocas de Aplicação } & \multicolumn{5}{|c|}{ Doses de etil-trinexapac $\left(\mathrm{g} \mathrm{ha}^{-1}\right)$} & \\
\hline & 0 & 75 & 150 & 225 & 300 & \\
\hline \multicolumn{7}{|c|}{ Emergência-Floração (dias) } \\
\hline $\mathrm{P}$ & $63,0 \mathrm{a}$ & $63,0 \mathrm{~b}$ & $63,0 \mathrm{c}$ & $63,0 \mathrm{c}$ & $64,0 \mathrm{c}$ & ns \\
\hline P-DF & $64,0 \mathrm{a}$ & $64,0 \mathrm{~b}$ & $64,5 \mathrm{~b}$ & $66,3 \mathrm{~b}$ & $66,3 \mathrm{~b}$ & $\mathrm{RL}^{*}(1)$ \\
\hline \multirow[t]{2}{*}{$\mathrm{DF}$} & $63,5 \mathrm{a}$ & 66,0 a & 67,0 a & $68,0 \mathrm{a}$ & 68,0 a & $\mathrm{RQ}^{*(2)}$ \\
\hline & \multicolumn{5}{|c|}{ Emergência-Colheita (dias) } & \\
\hline $\mathrm{P}$ & $93,0 \mathrm{~b}$ & $93,0 \mathrm{c}$ & $93,0 \mathrm{c}$ & $93,0 \mathrm{c}$ & $94,0 \mathrm{c}$ & $\mathrm{RL}^{*}(3)$ \\
\hline P-DF & 94,0 a & $94,0 \mathrm{~b}$ & $94,0 \mathrm{~b}$ & $95,0 \mathrm{~b}$ & $95,0 \mathrm{~b}$ & $\mathrm{RL}^{* *}(4)$ \\
\hline DF & $93,5 \mathrm{ab}$ & 97,0 a & 97,0 a & $97,0 \mathrm{a}$ & 97,0 a & $\mathrm{RQ}^{*}(5)$ \\
\hline
\end{tabular}

Médias seguidas de mesma letra nas colunas, não diferem estatisticamente entre si pelo teste de Tukey a $5 \%$. Ns: não signifcativo. ** e * significativo a $1 \%$ e $5 \%$ de probabilidade pelo teste $\mathrm{F}$ respectivamente. P: fase de perfilhamento ativo. P-DF: entre as fases de perfilhamento ativo e diferenciação floral. DF: fase de diferenciação floral. $R L=$ Regressão linear. $R Q=\operatorname{Regressão~Quadrática.~}\left({ }^{1}\right) y=63,65+2,25 x\left(R^{2}=0,85\right)$; $\left({ }^{2}\right) y=63,59+8,44 x-3,97 x^{2}\left(R^{2}=0,99\right) ;\left({ }^{3}\right) y=93,09-1,24 x\left(R^{2}=0,86\right) ;\left({ }^{4}\right) y=93,80+1,00 x\left(R^{2}=0,75\right) ; \quad\left({ }^{5}\right) y=93,90+9,00 x-5,56 x^{2}\left(R^{2}=0,86\right)$.

Na dose de $75 \mathrm{~g} \mathrm{ha}^{-1}$, o menor valor foi para a época de aplicação nas fases de perfilhamento e entre o perfilhamento ativo e a diferenciação floral, os quais diferiram da DF. Para doses dentro de épocas (Tabela 1), verificou-se que para as doses do regulador não houve efeito significativo com a época de aplicação em P. Em P-DF e DF os dados se ajustaram, respectivamente, à função linear e quadrática.

Observando os dados de número de dias para a colheita e épocas dentro de doses (Tabela 1), as doses de 75 a $300 \mathrm{~g} \mathrm{ha}^{-1}$ em DF retardaram a colheita de 3 a 4 dias em relação à aplicação em $P$ e de 2 a 3 dias em relação a P-DF. Para doses dentro de épocas, verificouse um ajuste linear, para épocas de aplicação nas fases $\mathrm{P}$ e P-DF e, quadrática para a DF, ocorrendo aumento do ciclo da cultura em função do aumento nas doses do regulador.

Quanto à altura de plantas e acamamento, houve interação significativa entre épocas de aplicação e doses do regulador de crescimento etiltrinexapac (Tabela 2). Considerando as doses dentro de épocas, verificou-se que na fase $\mathrm{P}$ as doses de aplicação do regulador de crescimento não foram significativas. Entretanto, a aplicação realizada na fase P-DF reduziu a altura de plantas, com ajuste dos dados a uma equação linear e alturas superiores a 1 $\mathrm{m}$. Também ocorreu redução na altura de plantas de arroz com a aplicação em DF e os dados se ajustaram a uma função quadrática, visto que a partir da dose de $150 \mathrm{~g} \mathrm{ha}^{-1}$ os valores observados foram inferiores a $1 \mathrm{~m}$. Para épocas dentro de doses de aplicação verificou-se que não houve diferença significativa para o tratamento sem uso do regulador. Para as doses 75 e $150 \mathrm{~g} \mathrm{ha}^{-1}$ não houve diferenças para a aplicação na fase P e P-DF, porém, diferiram de DF, na qual se obteve a menor altura de plantas. Entretanto, para as doses de 225 e $300 \mathrm{~g} \mathrm{ha}^{-1}$, houve diferença para as três épocas de aplicação, sendo observada menor altura para a aplicação do regulador em DF. As doses crescentes de etil-trinexapac causaram efeito na planta, promovendo, dessa forma, a redução na sua altura.

Comportamento semelhante foi observado por Alvarez (2003) que, estudando o efeito do etiltrinexapac na redução da altura da planta de arroz irrigado por aspersão, aplicado em DF, verificou que o regulador vegetal, na dose de $200 \mathrm{~g} \mathrm{ha}^{-1}$ de i.a., reduziu a altura da planta em $0,34 \mathrm{~m}$. Essa resposta é comum com o uso de reguladores vegetais, neste caso utilizados com a intenção de retardar o crescimento das plantas, sem ocasionar redução na produtividade (RADEMACHER, 2000; BIASI, 2002). Entretanto, BuzetTI et al. (2006) verificaram que a aplicação do regulador de crescimento cloreto de clormequat não influenciou na altura de plantas de duas cultivares de arroz de terras altas.

Em relação ao acamamento das plantas, verificou-se comportamento semelhante ao obtido para a altura das plantas (Tabela 2). Com relação a épocas dentro de doses, a partir da dose de $75 \mathrm{~g} \mathrm{ha}^{-1}$ já houve drástica redução no acamamento das plantas quando a aplicação foi realizada na diferenciação floral. No que se refere às doses dentro de épocas de aplicação, os dados se ajustaram à função linear para a aplicação na fase P-DF e equação quadrática quando a aplicação do regulador foi realizada em DF. 
Portanto, a aplicação de doses de 75 a $150 \mathrm{~g} \mathrm{ha}^{-1}$ do regulador de crescimento em DF minimiza ou elimina o problema do acamamento de plantas da cultivar Primavera.

Quanto ao teor de $\mathrm{N}$ nas folhas (Tabela 3) verificou-se que não houve efeito significativo da época de aplicação e de doses do regulador de crescimento utilizado, com os valores obtidos estando dentro do ideal preconizado por CANTARELLA e FURLANI (1996). Alvarez et al. (2007a), avaliando a influência do regulador de crescimento etil-trinexapac na distribuição de $\mathrm{N}\left({ }^{15} \mathrm{~N}\right)$ nas partes e na planta inteira de arroz, verificaram que a aplicação do regulador reduziu o acúmulo de ${ }^{15} \mathrm{~N}$ na panícula, promoveu a redistribuição do ${ }^{15} \mathrm{~N}$ absorvido e o aumento do ${ }^{15} \mathrm{~N}$ acumulado na raiz, colmo + bainha e folhas. No presente trabalho, o não-aumento no teor de $\mathrm{N}$ nas folhas pode ser consequência indireta da maior quantidade de panículas nas plantas tratadas com o regulador de crescimento. Essa situação representaria um dreno de $\mathrm{N}$ e assim impediria a redistribuição de $\mathrm{N}$ nas plantas.

Tabela 2. Interação entre doses do regulador de crescimento e épocas de aplicação em relação à altura de plantas e ao acamamento

\begin{tabular}{|c|c|c|c|c|c|c|}
\hline \multirow{2}{*}{ Épocas de Aplicação } & \multicolumn{5}{|c|}{ Doses de etil-trinexapac $\left(\mathrm{g} \mathrm{ha}^{-1}\right)$} & \\
\hline & 0 & 75 & 150 & 225 & 300 & \\
\hline \multicolumn{7}{|c|}{ Altura de plantas $(\mathrm{m})$} \\
\hline $\mathrm{P}$ & 1,36 a & 1,41 a & $1,40 \mathrm{a}$ & 1,39 a & $1,34 \mathrm{a}$ & ns \\
\hline P-DF & $1,38 \mathrm{a}$ & 1,39 a & $1,31 \mathrm{a}$ & $1,23 \mathrm{~b}$ & $1,16 \mathrm{~b}$ & $\mathrm{RL}^{* *}(2)$ \\
\hline DF & $1,34 \mathrm{a}$ & $1,16 \mathrm{~b}$ & $0,95 \mathrm{~b}$ & $0,87 \mathrm{c}$ & $0,80 \mathrm{c}$ & $\mathrm{RQ}^{* *(3)}$ \\
\hline \multicolumn{7}{|c|}{ Acamamento $^{(1)}$} \\
\hline $\mathrm{P}$ & $5,0 \mathrm{a}$ & $4,5 \mathrm{a}$ & $5,0 \mathrm{a}$ & 5,0 a & $4,0 \mathrm{a}$ & ns \\
\hline P-DF & $4,5 \mathrm{a}$ & $4,5 \mathrm{a}$ & $3,0 \mathrm{~b}$ & $0,5 \mathrm{~b}$ & $0,0 \mathrm{~b}$ & $\mathrm{RL}^{* *}(4)$ \\
\hline DF & $4,8 \mathrm{a}$ & $0,5 \mathrm{~b}$ & $0,0 \mathrm{c}$ & $0,0 \mathrm{~b}$ & $0,0 \mathrm{~b}$ & $\mathrm{RQ}^{* *(5)}$ \\
\hline
\end{tabular}

Médias seguidas de mesma letra nas colunas, não diferem estatisticamente entre si pelo teste de Tukey a 5\%. ns: não signifcativo. ** e *: significativo a $1 \%$ e $5 \%$ de probabilidade pelo teste F respectivamente. P: fase de perfilhamento ativo;. P-DF: entre as fases de perfilhamento ativo e diferenciação floral. DF: fase de diferenciação floral. RL=Regressão linear. RQ=Regressão Quadrática. $\left({ }^{1}\right)$ Escala de notas: $0=$ sem acamamento; $1=$ até $5 \%$ de plantas acamadas; $2=5 \%$ a $25 \%, 3=25 \%$ a $50 \% ; 4=50 \%$ a $75 \%$ e $5=75 \%$ a $100 \%$. A análise se refere aos dados transformados em $\sqrt{ } x+0,5 .\left({ }^{2}\right) y=1,42-0,20 x\left(R^{2}=0,93\right) .\left({ }^{3}\right) y=1,35-0,79 x+0,28 x^{2}\left(R^{2}=0,99\right) .\left({ }^{4}\right) y=5,10-4,33 x\left(R^{2}=0,91\right) . .\left({ }^{5}\right) y=4,34-11,96 x+7,14$ $x^{2}\left(R^{2}=0,91\right)$.

Tabela 3. Teor de $\mathrm{N}$ nas folhas, número de colmos e de panículas por metro quadrado e, perfilhamento útil em função a épocas de aplicação e doses de regulador de crescimento

\begin{tabular}{|c|c|c|c|c|c|}
\hline Causas de variação & & $\mathrm{N}$ foliar & Colmos & Panículas & Perfilhamento útil \\
\hline & & $\mathrm{g} \mathrm{kg}^{-1}$ & $\mathrm{~m}^{-2}$ & $\mathrm{~m}^{-2}$ & $\%$ \\
\hline \multirow[t]{3}{*}{ Épocas de Aplicação } & $\mathrm{P}$ & $37,3 \mathrm{a}$ & $277,2 \mathrm{a}$ & $253,0 \mathrm{a}$ & $92,0 \mathrm{a}$ \\
\hline & P-DF & $36,6 \mathrm{a}$ & $296,1 \mathrm{a}$ & $264,1 \mathrm{a}$ & $89,0 \mathrm{ab}$ \\
\hline & $\mathrm{DF}$ & $36,6 \mathrm{a}$ & 289,0 a & 243,1 a & $84,7 \mathrm{~b}$ \\
\hline \multirow[t]{5}{*}{ Doses de Etil-trinexapac $\left(\mathrm{g} \mathrm{ha}^{-1}\right)$} & 0 & 37,2 & $237,3^{(1)}$ & $215,0^{(2)}$ & 90,6 \\
\hline & 75 & 36,9 & 288,9 & 261,9 & 90,6 \\
\hline & 150 & 36,8 & 284,5 & 244,8 & 86,5 \\
\hline & 225 & 36,4 & 299,0 & 271,8 & 91,1 \\
\hline & 300 & 36,7 & 327,3 & 273,4 & 84,0 \\
\hline
\end{tabular}

Médias seguidas de mesma letra nas colunas, não diferem estatisticamente entre si pelo teste de Tukey a $5 \%$. P: fase de perfilhamento ativo. PDF: entre as fases de perfilhamento ativo e diferenciação floral. DF: fase de diferenciação floral. $\left({ }^{1}\right) y=249,42+63,31 x\left(R^{2}=0,85\right) . .\left({ }^{2}\right)$ y $=228,05+42,22 x$ $\left(\mathrm{R}^{2}=0,68\right)$. 
Considerando o número de colmos e panículas por metro quadrado (Tabela 3), houve apenas efeito das doses do regulador, com os valores se ajustando a uma função linear crescente. Entretanto, BUZETTI et al. (2006) estudaram doses de zero a $2 \mathrm{~L} \mathrm{ha}^{-1}$ de cloreto de clormequat, nas cultivares de arroz IAC 201 e IAC 202 e não verificaram diferença no número de panículas e, Alvarez et al. (2007b) estudaram reguladores vegetais e doses, na cultivar Primavera, e também não verificaram efeito no número de colmos e panículas por metro quadrado. Esses dados reforçam que o efeito do regulador de crescimento é dependente do momento e da dose de aplicação (Dunand, 2003) e cultivar (Rajala e Peltonen-SAinio, 2001). No trabalho de Alvarez et al. (2007 b), foi aplicado o etil-trinexapac no período de perfilhamento, enquanto no presente trabalho, o regulador foi utilizado no perfilhamento, entre o perfilhamento e a diferenciação floral e, na diferenciação floral e, no de BuZETTI et al. (2006) foi utilizado outro regulador, o cloreto de clormequat, com a aplicação parcelada aos 20 e 30 dias após a emergência das plântulas de arroz.

O perfilhamento útil foi influenciado pela época de aplicação (Tabela 3), sendo o maior valor observado para a aplicação do regulador em P e o menor em DF e, ambos, não diferiram da aplicação em P-DF.

Os resultados indicam que o regulador de crescimento influenciou nos componentes produtivos, no número de colmos e nas panículas por metro quadrado e, no perfilhamento útil, os quais, normalmente se correlacionam com a produtividade. O resultado dessas alterações é o aparecimento de plantas mais compactas, com melhor direcionamento dos fotoassimilados para a produção de grãos (ZAGONEL et al., 2002).
O número de grãos totais e cheios por panícula foi influenciado apenas pelas doses do regulador (Tabela 4). Observou-se menor número de grãos por panícula quanto maior a dose utilizada, com os dados se ajustando à equações lineares decrescentes. Resultado semelhante foi observado por Alvarez (2003) que verificou influência negativa neste componente da produção. Já BuzetTi et al. (2006) verificaram que a aplicação de regulador de crescimento não influenciou o comprimento da panícula e para o número de grãos por panícula houve ajuste à equação linear decrescente, no primeiro ano e, crescente no segundo, indicando existência de interação entre o regulador de crescimento e as condições climáticas. Os autores verificaram que no primeiro ano, as plantas foram maiores, com melhor perfilhamento, maior índice de fertilidade e maior produtividade de grãos. Vale ressaltar que no presente estudo houve aumento no número de colmos e de panículas em função do aumento nas doses do regulador de crescimento o que pode ter contribuído para a redução no número de grãos por panícula.

Em relação ao número de grãos chochos por panícula verificou-se efeito significativo entre época de aplicação e doses (Tabela 5). A aplicação de 225 e 300 $\mathrm{g} \mathrm{ha}^{-1}$ do regulador em DF proporcionou maior número de grãos chochos por panícula. Para doses dentro de épocas de aplicação, os dados se ajustaram a equações lineares para as aplicações realizadas nas fases P e DF, sendo decrescente no primeiro caso e crescente no último. Já para a aplicação realizada na fase P-DF os dados se ajustaram à função quadrática. Segundo Alvarez et al. (2007b), o aumento na proporção de grãos chochos pode ser resultado dos efeitos do regulador na formação de flores (estames e ovários) e na meiose, o que justificaria o aumento desse tipo de grão quando a aplicação do regulador foi realizada em DF.

Tabela 4. Grãos por panícula em relação a épocas de aplicação e doses de regulador de crescimento

\begin{tabular}{lcrr}
\hline Causas de variação & & \multicolumn{2}{c}{ Grãos por panícula } \\
\cline { 3 - 4 } Épocas de Aplicação & P & Totais & 142,0 a \\
& P-DF & 163,3 a & 138,8 a \\
& DF & 157,9 a & 137,4 a \\
Doses de Etil-trinexapac $\left(\mathrm{g} \mathrm{ha}^{-1}\right)$ & 0 & $163,8 \mathrm{a}$ & $154,8^{(2)}$ \\
& 75 & $180,4^{(1)}$ & 145,1 \\
& 150 & 168,5 & 140,3 \\
& 225 & 161,2 & 128,5 \\
& 300 & 147,8 & 128,3 \\
\hline
\end{tabular}

Médias seguidas de mesma letra nas colunas, não diferem estatisticamente entre si pelo teste de Tukey a $5 \%$. P: fase de perfilhamento ativo. PDF: entre as fases de perfilhamento ativo e diferenciação floral. DF: fase de diferenciação floral. $\left({ }^{1}\right)$ y $=177,80-26,85 x\left(R^{2}=0,91\right) . .\left({ }^{2}\right)$ y $=$ $153,30-23,20 \times\left(R^{2}=0,95\right)$. 
Tabela 5. Interação entre doses do regulador de crescimento e épocas de aplicação em relação ao número de grãos chochos por panícula

\begin{tabular}{|c|c|c|c|c|c|c|}
\hline \multirow{2}{*}{ Épocas de Aplicação } & \multicolumn{5}{|c|}{ Doses de etil-trinexapac $\mathrm{g} \mathrm{ha}^{-1}$} & \\
\hline & 0 & 75 & 150 & 225 & 300 & \\
\hline $\mathrm{P}$ & 24,9 a & $24,3 \mathrm{a}$ & $24,2 \mathrm{a}$ & $17,7 \mathrm{ab}$ & $15,5 \mathrm{~b}$ & $\mathrm{RL} * *(1)$ \\
\hline P-DF & $30,1 \mathrm{a}$ & $20,0 \mathrm{a}$ & $14,9 \mathrm{a}$ & $14,7 \mathrm{~b}$ & $16,0 \mathrm{~b}$ & $\mathrm{RQ} *(2)$ \\
\hline DF & $22,1 \mathrm{a}$ & $25,9 \mathrm{a}$ & $23,6 \mathrm{a}$ & $25,4 \mathrm{a}$ & $35,2 \mathrm{a}$ & $\mathrm{RL} * *(3)$ \\
\hline
\end{tabular}

Médias seguidas de mesma letra nas colunas, não diferem estatisticamente entre si pelo teste de Tukey a $5 \%$. ** e * significativo a $1 \%$ e $5 \%$ de probabilidade pelo teste F respectivamente. P: fase de perfilhamento ativo. P-DF: entre as fases de perfilhamento ativo e diferenciação floral. DF: fase de diferenciação floral. RL=Regressão linear. $R Q=$ Regressão Quadrática. $\left({ }^{1}\right)$ y $=26,35-8,42 \times\left(R^{2}=0,84\right) .\left({ }^{2}\right)$ y $=29,77-37,54 x+22,02 x^{2}\left(R^{2}=0,99\right)$; (3) $y=21,30+8,58 x\left(R^{2}=0,63\right)$..

No que se refere aos valores obtidos para massa de cem grãos e massa hectolítrica houve efeito significativo para época de aplicação e também para doses utilizadas (Tabela 6). Quanto à época de aplicação os maiores valores, para massa de cem grãos e hectolítrica, foram obtidos com aplicação em P-DF. No caso das doses os valores se ajustaram às equações quadráticas tanto para a massa de 100 grãos quanto para a massa hectolítrica. O aumento na massa de cem grãos e massa hectolítrica em função das doses do regulador pode ser explicado pela redução na altura de plantas. Assim, os fotoassimilados que seriam destinados à alongação da planta na ausência de regulador foram destinados para melhorar o enchimento dos grãos na presença do regulador de crescimento e, como conseqüência resultando em maior massa de cem grãos e massa hectolítrica.

Tabela 6. Massa de 100 grãos e hectolítrica em relação a épocas de aplicação e doses de regulador de crescimento

\begin{tabular}{|c|c|c|c|}
\hline \multirow{2}{*}{ Causas de variação } & & \multicolumn{2}{|c|}{ Massa } \\
\hline & & 100 grãos g & Hectolítrica $\mathrm{kg} 100 \mathrm{~L}^{-1}$ \\
\hline \multirow[t]{3}{*}{ Épocas de Aplicação } & $\mathrm{P}$ & $2,5 \mathrm{~b}$ & $54,9 \mathrm{~b}$ \\
\hline & P-DF & $2,6 \mathrm{a}$ & $57,1 \mathrm{a}$ \\
\hline & DF & $2,5 \mathrm{~b}$ & $54,7 \mathrm{~b}$ \\
\hline \multirow[t]{5}{*}{ Doses de Etil-trinexapac (g ha ${ }^{-1}$ ) } & 0 & $2,4\left({ }^{1}\right)$ & $51,8\left({ }^{2}\right)$ \\
\hline & 75 & 2,5 & 56,9 \\
\hline & 150 & 2,6 & 56,0 \\
\hline & 225 & 2,6 & 55,9 \\
\hline & 300 & 2,6 & 57,2 \\
\hline
\end{tabular}

Médias seguidas de mesma letra nas colunas, não diferem estatisticamente entre si pelo teste de Tukey a $5 \%$. P: fase de perfilhamento ativo. P-DF: entre as fases de perfilhamento ativo e diferenciação floral. DF: fase de diferenciação floral. $\left({ }^{1}\right) \mathrm{y}=2,39+0,51 \mathrm{x}-0,28 \mathrm{x}^{2}\left(\mathrm{R}^{2}=0,96\right)$. $\left({ }^{2}\right) \mathrm{y}=52,65+9,59 x-5,27 x^{2}\left(R^{2}=0,68\right)$.

Quanto à produtividade, houve interação significativa entre as épocas de aplicação e as doses do regulador de crescimento etil-trinexapac (Tabela 7). Para época dentro de doses, verificou-se que não houve diferenças entre as épocas de aplicação até a dose de $150 \mathrm{~g} \mathrm{ha}^{-1}$ do regulador (Tabela 7). Apenas nas doses de 225 e $300 \mathrm{~g} \mathrm{ha}^{-1}$ a aplicação do regulador de crescimento propiciou diferenças de produtividade. A redução excessiva do colmo e o retardamento do espigamento são conseqüências da aplicação tardia e podem, dependendo das condições, provocar prejuízos na produtividade de grãos. Alvarez et al. (2007b) também mencionam que o efeito de redução na produtividade de grãos acarretada pela aplicação do etiltrinexapac pode estar associada às doses empregadas, entretanto, esses valores comparados aos da literatura foram maiores. Para doses dentro de época de aplicação, verifica-se que os dados se ajustaram à equação linear crescente para a aplicação na fase P-DF e equação quadrática para aplicação em DF. Entretanto, BuZETTI et al. (2006) verificaram que a aplicação de regulador de crescimento (cloreto de clormequat) não influencia a produtividade da cultura do arroz. Da mesma forma, não houve prejuízo na produtividade da cultura de trigo com a aplicação do etil-trinexapac, sendo observado efeito positivo do regulador de crescimento na produtividade do trigo, provavelmente resultado do controle de acamamento, pela redução do porte das plantas (EMBRAPA, 2003) e pelo aumento do número de espigas por metro (ZAGONEL et al., 2002). 
Tabela 7. Interação entre doses do regulador de crescimento e épocas de aplicação em relação a produtividade de grãos

\begin{tabular}{|c|c|c|c|c|c|c|}
\hline \multirow{2}{*}{ Épocas de Aplicação } & \multicolumn{5}{|c|}{ Doses de etil-trinexapac $\mathrm{g} \mathrm{ha}^{-1}$} & \\
\hline & 0 & 75 & 150 & 225 & 300 & \\
\hline $\mathrm{P}$ & 4475 a & 4590 a & 3929 a & $4558 \mathrm{ab}$ & $4529 \mathrm{~b}$ & ns \\
\hline P-DF & 4345 a & 4527 a & 4138 a & 5868 a & 5996 a & $R L^{* *(1)}$ \\
\hline DF & $4212 \mathrm{a}$ & 5477 a & 4957 a & $4489 \mathrm{~b}$ & $3354 \mathrm{~b}$ & $R Q *(2)$ \\
\hline
\end{tabular}

Médias seguidas de mesma letra nas colunas, não diferem estatisticamente entre si pelo teste de Tukey a 5 \%. ns: não siginifcativo. ** e *: significativo a $1 \%$ e $5 \%$ de probabilidade pelo teste F respectivamente. P: fase de perfilhamento ativo. P-DF: entre as fases de perfilhamento ativo e diferenciação floral. DF: fase de diferenciação floral. $R L=$ Regressão linear. $R Q=$ Regressão Quadrática. $\left({ }^{1}\right) y=4.046,20+1.547,90 x\left(R^{2}=0,69\right)$; $\left(^{2}\right) y=4.360,41+3.620,17 x-3.768,16 x^{2}\left(R^{2}=0,91\right)$.

\section{CONCLUSÃO}

O etil-trinexapac deve ser aplicado na dose de $150 \mathrm{~g} \mathrm{ha}^{-1}$, por ocasião do início da diferenciação floral da cultivar de arroz Primavera, considerando a redução na altura de plantas, a eliminação do acamamento e a produtividade de grãos.

\section{AGRADECIMENTOS}

À UNESP-Campus de Ilha Solteira e FAPESP, pelos recursos humanos e materiais e, ao $\mathrm{CNPq}$, pela concessão da bolsa de mestrado.

\section{REFERÊNCIAS}

ALVAREZ, R.C.A. Absorção, distribuição e redistribuição de nitrogênio $\left({ }^{15} \mathrm{~N}\right)$ em cultivares de arroz de terras altas em função da aplicação de reguladores vegetais. 2003. $87 \mathrm{f}$. Tese (Doutorado em Agronomia/Agricultura) - Faculdade de Ciências Agronômicas, Universidade Estadual Paulista, Botucatu, 2003.

ALVAREZ, R.C.F.; CRUSCIOL, C.A.C; OCHEUZE, P.C.; RODRIGUES, J.D.; ALVAREZ, A.C.C. Influência do etiltrinexapac no acúmulo, na distribuição de nitrogênio $\left({ }^{15} \mathrm{~N}\right)$ e na massa de grãos de arroz de terras altas. Revista Brasileira de Ciências do Solo, v.31, p.1487-1496, 2007a.

ALVAREZ, R.C.F.; CRUSCIOL, C.A.C.; RODRIGUES, J.D.; ALVAREZ, A.C.C. Aplicação de reguladores vegetais na cultura de arroz de terras altas. Acta Scientiarum Agronomy, v.29, p.241-249, 2007b.

BIASI, A. L. Reguladores de crescimento vegetal. In: WACHOWICZ, C. M.; CARVALHO, R. I, N. (Org.). Fisiologia vegetal produção e pós-colheita. Curitiba: Champagnat, 2002. p.63-94.

BRESEGHELLO, F.; CASTRO, E. M.; MORAIS, O. P. Cultivares de arroz. In: BRESEGHELLO, F.;STONE, L. F. Tecnologia para arroz de terras altas. Santo Antônio de Goiás: Embrapa Arroz e Feijão, 1998. p.41-53.
BUZETTI, S.; BAZANINI, G.C.; FREITAS, J.G.; ANDREOTTI, M.; ARF, O.; SÁ, M.E.; MEIRA, F.A. Resposta de cultivares de arroz a doses de nitrogênio e do regulador de crescimento cloreto de clormequat. Pesquisa Agropecuária Brasileira, v.41, p.1731-1737, 2006.

CANTARELLA, H.; FURLANI,P.R. Arroz de sequeiro. In: RAIJ, B. van; CANTARELLA, H.; GUAGGIO, J.A.; FURLANI, A.M.C. (Coord.). Recomendações de adubação e calagem para o Estado de São Paulo. 2.ed. Campinas: Instituto Agronômico \& Fundação IAC, 1996. 285p.

CARVALHO, L. H.; CHIAVEGATO, E.J.; CIA, E.; KONDO, J. I.; SABINO, J.C., PITTINELLI JUNIOR, A.; BORTOLETTO, N.; GALLO, P. B. Fitorreguladores de crescimento e capação na cultura algodoeira. Bragantia, v.53, p.247-254, 1994.

DAVIES. P. J. Plant hormones physiology biochemistry and molecular biology. 2.ed. Netherlands: Klumer Academic Publishes, 1995. $823 \mathrm{p}$.

DUNAND, R. T. Influence of growth suppression on panicle growth, plant stature, and crop production in rice. In: PROCEEDINGS OF THE ANNUAL MEETING PLANT GROWTH REGULATION SOCIETY OF AMERICA, 38., 2003, Vancouver. Proceedings... LaGrange: The Plant Growth Regulation Society of America, 2003. p.72.

EMPRESA BRASILEIRA DE PESQUISA AGROPECUÁRIA Embrapa. Sistema brasileiro de classificação de solos. Rio de Janeiro: EMBRAPA/CNPSO, 1999. 412p.

EMPRESA BRASILEIRA DE PESQUISA AGROPECUÁRIA Embrapa. Circular técnica On-line. Passo Fundo: EMBRAPA/ TRIGO, 2003. (Circular Técnica, 14)

LAMAS, F.M. Estudo comparativo entre cloreto de mepiquat e cloreto de chlormequat aplicados no algodoeiro. Pesquisa Agropecuária Brasileira, v.36, p.265-272, 2001.

MALAVOLTA, E.; VITTI, G.C.; OLIVEIRA, S.A. Avaliação do estado nutricional das plantas: princípios e aplicações. Piracicaba: Potafós, 1997. 319p.

NAQVI, S. S. M. Plant growth hormones: growth promotors and inibitors. In: PESSARAKLI, M. Handbook of plant and crop physiology. New York: Marcel Dekker, 1994. p.527-556. 
RADEMACHER, W. Growth retardants: effects on gibberellin biosynthesis and other metabolic pathways. Annual Review of Plant Physiology and Plant Molecular Biology, v. 51, p. 501-531, 2000

RAIJ, B. van; QUAGGIO, J.A. Métodos de análises de solo para fins de fertilidade. Campinas: IAC, 1983. p.1-31. (Boletim Técnico, 81)

RAJALA, A.; PELTONEN-SAINIO, P. Plant growth regulator effects on spring cereal root and shoot growth. Agronomy Journal, v. 93, p.936-943, 2001.

REDDY, V. R.; BAKER, D. N.; HODGES, H. F. Temperature and mepiquat chloride effects on cotton canopy architecture. Agronomy Journal, v. 82, p. 190-195, 1990.

REDDY, V. R.; TRENT, A.; ACOCK, B. Mepiquat chloride and irrigation versus cotton growth and development. Agronomy Journal, v. 84, p. 930-933, 1992.

RESENDE, P. A. P.; SOARES, J. E.; HUDETZ, M. Moddus, a plant growth regulator and management tool for sugarcane production in Brasil. International Sugar Journal, v. 103, p.26, 2001.

RODRIGUES, R.A.F.;SORATTO, R.P.; ARF, O. Manejo de água em arroz de terras altas no sistema de plantio direto, usando o tanque classe A. Engenharia Agrícola, v.24, p.546-556, 2004.

TAIZ, L.; ZEIGER, E. Plant physiology. 2. ed. Sunderland: Sinauer Associates, 1998. 792p.

ZAGONEL, J.; VENANCIO, W.S.; KUNZ, R.P.; TANAMAT, H. Doses de nitrogênio e densidades de plantas com e sem um regulador de crescimento afetando o trigo, cultivar OR-1. Ciência Rural, v.32, p.25-29, 2002.

WALLACE, T. P.; SNIPES, C. E.; WHITE, B. W. Effects of singlemultiple applications of mepiquat chloride on Mississipi cotton. Research Reports-Mississipi Agricultural Foresty Experiment Station, v.18, p.5, 1993.

YORK, A. C. Cotton cultivar response to mepiquat chloride. Agronomy Journal, v.75, p. 663-667, 1983. 